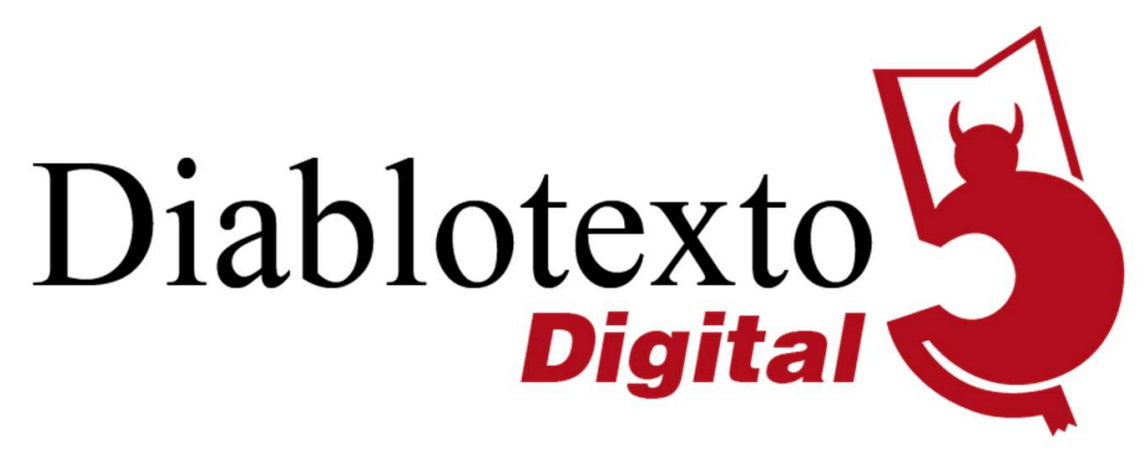

\title{
Sueños para una nueva danza española: la dramaturgia de El desertor (1930), de Felipe Ximénez de Sandoval*
}

\author{
Dreams for a New Spanish Dance: Dramaturgy of El desertor (1930), by Felipe \\ Ximénez de Sandoval \\ AlejandRo Coello HeRnándeZ \\ INSTITUTO DE HISTORIA, CSIC / UNIVERSIDAD COMPLUTENSE DE MADRID
}

\begin{abstract}
Resumen: En la obra literaria de Felipe Ximénez de Sandoval (1903-1978), se puede observar una dedicación especial a las artes escénicas. Más allá de su faceta de dramaturgo, se relacionó con los grandes músicos españoles y se interesó por la danza española. Por eso, escribió dos dramaturgias de ballet: El desertor (1930), sin representación, y La rosa viva (1966), coreografiado por Mariemma. Aunque este último ballet no ha sido hallado, El desertor ha sido localizado en los fondos de la bailarina Antonia Mercé la Argentina, para quien lo compuso con música de Gustavo Pittaluga. Este artículo estudia la vinculación del autor con la danza española y analiza la dramaturgia del ballet de 1930 .
\end{abstract}

Palabras clave: danza española, ballet, dramaturgia, Ballets Espagnols.

Abstract: In the literary work of Felipe Ximénez de Sandoval (1903-1978), we observe a special dedication to performing arts. Beyond his facet as playwright, he was in contact with the greatest Spanish musicians and was interested in Spanish dance. Thereby, he wrote two dramaturgies for ballet: El desertor (1930), without representation, and La rosa viva (1966), choreographed by Mariemma. Although this last ballet's location is unknown, El desertor was found in the archives of Antonia Mercé la Argentina. He created it for her with Gustavo Pitalluga's music. This article studies the connection between the author and the Spanish dance and analyses the dramaturgy of this ballet.

Key words: Spanish dance, ballet, dramaturgy, Ballets Espagnols

\footnotetext{
* Este artículo está realizado en el marco del proyecto de investigación P.E. I+D+i Tras los pasos de la Silfide. Una historia de la danza en España, 1836-1936 (ref. PGC2018-093710-A-I00), financiado por el Ministerio de Ciencia, Innovación y Universidades (MCIU), la Agencia Estatal de Investigación (AEI) y el Fondo Europeo de Desarrollo Regional (FEDER) de la Unión Europea. De la misma manera, está adscrito al proyecto P. E. I+D+I Acciones de Dinamización "Europa Excelencia" Ballets Españoles (1927-1929): una compañía de danza para la internacionalización del arte moderno (ref. ERC2018-092829), financiado por MCIU y AEI.
} 
Moverse para detenerse: la Vida. Suspender definitivamente el movimiento: la Muerte.

Imágenes del movimiento (1928),

Felipe Ximénez de Sandoval

Las relaciones entre teatro, literatura y danza en España han comenzado a estudiarse sistemáticamente en las últimas décadas con pocos resultados en lo que respecta a metodologías para el estudio del texto dramático que soporta los ballets de danza española. Quizá los únicos intentos de teorizar sobre este particular objeto de estudio hayan sido el de Hellín Rubio (2016) y Bethencourt Pérez (2016), cuya trascendencia en los estudios del texto balletístico está aún por valorarse. En este artículo, debido a la ausencia teórico-bibliográfica, se ha decidido analizar El desertor desde el contexto creativo y la producción conocida de su autor, Ximénez de Sandoval. Se parte, por ello, de que el texto balletístico se puede afrontar desde la semiótica teatral, aunque con la absoluta consciencia de que la danza, en definitiva, es un arte autónomo.

No obstante, cabría pensar a priori que teatro y danza, en cuanto a los signos semióticos, difieren tan solo en la prominencia de los signos lingüísticos y paralingüísticos. Mas, al contrario, las coordenadas de la escena actual derriban esta concepción con géneros híbridos, como el teatro-danza o el teatro físico en donde el cuerpo adquiere una significación central en detrimento de la palabra. En cualquier caso, esta disquisición sigue sin obtener conclusiones claras, aunque se puede presuponer que en el caso de la danza los signos gestuales, proxémicos y mímicos asociados a la expresión coreográfica prevalecen al resto y coexisten en particular armonía con los acústicos.

En este caso, en que el objeto de estudio se centra en danza escénica de la Edad de Plata, resulta aún más compleja la relación entre teatro y danza, ya que esta última, en el caso español, se encuentra en un proceso de transición en busca de la independencia artística. Esta circunstancia se une a dos de las características que Fischer-Lichte ([1983] 1996) atribuye al teatro y que se pueden trasladar al repertorio dancístico que analizo: por un lado, la "actualidad absoluta", que convierte tanto a una como a otra disciplina en artes efímeras cuyas huellas materiales son de difícil rastreo y se encuentran dispersas; y, por otro lado, la "duplicación", que constata la estrecha relación entre teatro y danza 
con la cultura y, por ende, con el código de la época en que se formularon estos trabajos escénicos.

Además, como ya se ha comentado, en las últimas décadas se ha trabajado para intentar valorar la influencia del teatro en el proceso emancipatorio de la danza española y en la consolidación del ballet en el ámbito nacional. Asimismo, se ha buscado encontrar la manera en que esta relación transmedial ha afectado a la concepción coreográfica, aspecto que resulta imposible estudiar en un ballet, como El desertor (1930), que no llegó a representarse. Según Inés Hellín Rubio (2016: 153),

el proceso de transducción del texto o libreto que soporte el argumento dramático a su escenificación, [...] va a desembocar en nuevas formas y medios discursivos de la técnica dancística empleada, y va a consolidar los cánones preexistentes al proyecto dramático del ballet.

En conclusión, de cara a comprender las dramaturgias para danza en la Edad de Plata, es necesario recopilar la mayor cantidad de documentación dispersa y describir el contexto de creación. En este caso, analizar la dramaturgia de El desertor, de Felipe Ximénez de Sandoval (1903-1978), resulta un trabajo complejo, ya que su propia obra literaria ha sido poco atendida, y, hasta ahora, no ha sido relacionado con la danza española de los años veinte y treinta. Por tanto, mi objetivo consiste en esbozar las relaciones de Ximénez de Sandoval con la escena dancística y musical y presentar un primer estudio dramatúrgico del ballet, centrado principalmente en los imaginarios explorados por el autor.

\section{Felipe Ximénez de Sandoval y el mundo de la danza}

Felipe Ximénez de Sandoval fue uno de los jóvenes intelectuales que bien podrían incluirse en el marbete de "Generación del 27" o la promoción de la Segunda República, aunque su aportación literaria en la actualidad sea desconocida. Además, formó parte de la "corte literaria" de José Antonio Primo de Rivera (Carbajosa y Carbajosa, 2003), lo que explica sus lazos con el ideólogo falangista que derivaron en el texto José Antonio (biografía apasionada) que se publicó en 1941 convirtiéndose en una de las primeras biografías de Primo de Rivera. Si bien ha sido conocido por su narrativa, con títulos como Tres mujeres más Equis (1930), Los nueve puñales (1936) o Camisa azul (1939), también fue 
un reconocido dramaturgo por piezas como Robinsón (1928) y Camino de Compostela (1954) o, en colaboración con Pedro Sánchez de Neyra, Oretes I (1930), Mercedes la gaditana (1932), Bacarrat (1933) y El pájaro pinto (1936).

Sin embargo, la mayor parte de la producción de Ximénez de Sandoval continúa sin reeditarse y numerosas obras teatrales no han sido localizadas hasta ahora ${ }^{1}$.

En cuanto a su relación con el mundo de la danza española, se conocen pocos datos. La mayoría de las noticias que se tienen han sido rastreadas a través de la prensa y las revistas en las que publicó en los años veinte y treinta. En cualquier caso, en los años sesenta, aún señalaba la necesidad de crear un ballet nacional que, según su perspectiva, se había intentado en diversas ocasiones frustradas "principalmente por la falta de medios económicos y la carencia de un director capaz de imponer la disciplina a los bailarines" (Sandved, 1962: 211-212, s. v. ballet). Esta consciencia, compartida con otras tentativas como las de Max Aub o Rivas Cherif, se vio materializada sin duda en El desertor en que se observa esa voluntad de innovar desde la tradición y con imaginarios de moda en el periodo de entreguerras. No obstante, cabe destacar que la escritura de Ximénez de Sandoval recibió influencias divergentes desde el romanticismo o el simbolismo hasta de las vanguardias, en especial del futurismo, aunque siempre las rechazó "porque vanguardia en Arte supone -y sépanlo de una vez quienes con otros fines intenten adscribirse a ella- 'amar al Arte sobre todas las cosas"' (VV. AA., 1930: 3). Esta amalgama de estéticas se refleja en El desertor, que se configura como un texto sui generis.

El comienzo del interés de Ximénez de Sandoval por la danza está íntimamente relacionado a su gusto musical, ya que es probable que fuese la música el motivo que lo llevó a escribir un ballet. La primera referencia que he logrado rescatar, hasta ahora, de esta atracción musical se puede encontrar en un texto que el autor escribió en abril de 1928 para un programa de mano: el 30 de ese mismo mes se estrenó el Cuarteto Flonzaley que había creado el joven Ernesto Halffter, de veintitrés años, dentro de las actividades de la Asociación

\footnotetext{
${ }^{1}$ Algunas de ellas son La segunda primera noche (ca. 1927), Sequía (ca. 1928), Dafnis, Cloe y Compañía (ca. 1929), El doctor Satanello (ca. 1929) en colaboración con Sánchez Neyra, Ficha de archivo (1930) en colaboración con Sánchez Neyra, El beso (1937) o Vuelo nocturno (1946).
} 
de Cultura Musical. Precisamente en él elogiaba al compositor por apartarse del "periodo de las estridencias de mal gusto, de la obra sin forma ni medida, del capricho arbitrario, que solo tiene por finalidad un renombre ficticio de escándalo" (Ximénez de Sandoval, 1928). Ya en este programa de mano el autor madrileño anunciaba que Halffter estrenaría pronto su ballet Sonatina. En efecto, el 18 de junio de 1928 se representó por primera vez en París el ballet por la compañía Ballets Espagnols de Antonia Mercé, la Argentina. Este dato, como se comentará, resulta definitivo en la composición de El desertor.

En diciembre de ese mismo año, según una noticia del 22 de diciembre de 1928 en $A B C$, se publica la nueva Junta directiva de la Asociación de Cultura Musical, en la que Ximénez de Sandoval ostentó el cargo de secretario. Cabe suponer que tras un año de vinculación lograra acceder al cargo con el aval de una prometedora carrera dedicada a la abogacía que, según el registro del Colegio de Abogados de Madrid, comenzó en 1925.

En junio de 1930, escribió un artículo en La Gaceta Literaria en donde remarcaba la importancia de Antonia Mercé, la Argentina, como exportadora de la identidad española. Además, el autor recalcaba el desinterés que había dentro de España por el trabajo de la Argentina, y no resulta baladí este dato si se tiene en cuenta que ya en 1929 se disolvió el proyecto de la compañía Ballets Espagnols de la bailarina por su insostenibilidad económica, incluso después de haber cosechado grandes éxitos en giras por todo el mundo con ballets como El fandango de candil (1927), escrito por Rivas Cherif, compuesto por Durán y escenografía y figurinismo de Néstor de la Torre, o Triana (1929), dramaturgia y orquestación de Enrique Fernández Arbós sobre Iberia, de Isaac Albéniz, con decorados y vestuario del pintor canario. Estos fueron hitos que, treinta años después, Sandoval reconoció como pioneros en el ballet español (Sandved, 1962: 212, s. v. ballet). En el artículo publicado en La Gaceta Literaria, continuaba su queja:

¡Lástima que Gustavo Pittaluga no haya tenido todavía ocasión de darnos a conocer la versión de orquesta de su ballet La romería de los cornudos! Lamentamos lo menos, lo hacedero, ya que presencia una representación del ballet por la compañía de nuestra genial Antonia Argentina, para quien está escrito expresamente, parece, hoy por hoy, un sueño. Nuestra gran bailarina paseará por todos los escenarios de Europa —menos por los españoles, a no 
ser que se haga uno de los muchos milagros que en España no suelen hacersesu repertorio de bailetes españoles, en el que figurarán los nombres de casi todos los músicos españoles de la actual promoción - Halffter, Bautista, Pittaluga, Durán, Bacarisse, Remacha- junto a los de Albéniz y Falla, con decorados de Néstor, Andréu, Bacarisas, etc. (Ximénez de Sandoval, 1930a)

Esta lamentación no parece insustancial porque en esas fechas Pittaluga estaba componiendo la partitura de El desertor. Además, cabe pensar que el dramaturgo conocía bien la poética de la Argentina que consistía en "el lenguaje de las líneas", como tituló una conferencia suya y que responde a esa búsqueda de la estilización de lo popular influenciada por su formación clásica. Años más tarde, el escritor resumió con acierto el ideal creativo de la bailarina como el proceso de "depurar y perfeccionar las danzas folklóricas españolas para elevarlas a una categoría más alta" (Sandved, 1962: 1568, s. v. Mercé).

Hasta ahora, el único dato que he logrado rescatar de la relación de Ximénez de Sandoval con la figura de Antonia Mercé, a quien dedicó su ballet, es su asistencia a un homenaje que se celebró en su honor, lo que no quiere decir que tuviesen una relación previa o espitolar. El acto tuvo lugar el 2 de diciembre de 1931 en el Círculo de Bellas Artes de Madrid y fue organizado por diversos artistas madrileños para exaltar su "significación españolísima" ( $A B C$, 1931) y su capacidad para universalizar el arte español sin abandonar sus raíces. Destaca que la nota de prensa señale este aspecto, ya que Antonia Mercé llegó a afirmar, incluso antes de la creación de los Ballets Espagnols en 1927, que "he presentado en el extranjero una España que para muchísima gente culta, incluidos españoles, es 'más España' que la España de veras" (Mercé y Luque, 1926) ${ }^{2}$. Entre los asistentes al homenaje, se mencionan a artistas que habían colaborado con la Argentina: Enrique Fernández Arbós, libretista y arreglista de Triana, y su esposa Ela; el escritor Tomás Borrás, que compuso el libreto de Juerga; el ya mencionado Gustavo Pittaluga; la bailarina Irene Ibáñez; o el compositor de Juerga, Julián Bautista. A su vez, se cita a otros intelectuales como Margarita Nelken o Luis de Tapia.

Ximénez de Sandoval fue, muy probablemente, un gran admirador de Antonia Mercé y de la huella que dejó el mito creado en torno a ella. En 1962,

\footnotetext{
${ }^{2}$ cf. Rivas Cherif (1931) sobre la Argentina como embajadora de la cultura española.
} 
cuando se publica en España El mundo de la música: guía musical, redactado y publicado bajo la dirección de Kjell B. Sandved, Ximénez de Sandoval no solo asume la labor de traducción, profesión a la que dedicó más tiempo durante la dictadura franquista, sino que se encargó de la ampliación de la parte española. Según la nota de traducción -lo que explica por qué cito como suyas las palabras de esta publicación-, decidió subsanar las "lagunas" de la edición original por la falta de compositores, intérpretes y bailarines españoles. Destaco, precisamente por su relación con la Argentina, la inclusión de Óscar Esplá, Enrique Fernández Arbós, su pianista durante cinco años Luis Galve, así como a las bailarinas Mariemma, Encarnación López Júlvez la Argentinita y a la misma Antonia Mercé. De ella, afirmará que "pocos artistas españoles han gozado de fama más universal que 'la Argentina', a quien los más gloriosos escritores dedicaron palabras de entusiástica admiración, considerándola —con justiciacomo el símbolo de la danza española» (Sandved, 1962: 1571, s. v. Mercé).

Ximénez de Sandoval tal vez escribió El desertor con ese afán juvenil de colaborar en el proyecto de la Argentina como un trasunto de lo español, de una consciencia de la proyección internacional que la bailarina exportaba de su nación. Aportó, así, un grano de arena para la consolidación de la danza escénica en España y, sobre todo, para la investigación de nuevos imaginarios de la españolidad.

Asimismo, cabe señalar que la propia Argentina se rodeó de creadores escénicos con el fin de aprehender de los códigos teatrales todo aquello que pudiese beneficiar a la danza, con el fin de crear una versión española de los Ballets Russes de Diaghilev:

En el momento que me decidí a realizarlo [el proyecto de los Ballets Espagnols], me puse en comunicación con la juventud literaria, musical y pictórica, los que tenían las tendencias más interesantes dentro del arte teatral moderno. Siempre he creído que España podía, como Rusia, inspirar un espectáculo lleno de carácter, de genialidad y de fuerza. (Mercé y Luque, s.a.)

Por eso, entre sus colaboradores, podemos señalar a jóvenes veinteañeros, como Ernesto Halffter, Gustavo Durán, Julián Bautista o el mismo Ximénez de Sandoval, o treintañeros, como Cipriano Rivas Cherif, Tomás Borrás, Manuel Fontanals, Fernando Remacha o los primos Mauricio y Salvador 
Bacarisse. La Argentina supo desde el primer momento que quiso poner en marcha los Ballets Espagnols que debería rodearse de los mejores artistas del momento "con el objetivo de basarse en lo mejor de la cultura española de renombre internacional" (Murga Castro, 2017: 142). Este objetivo se prolongó en el tiempo más allá de la compañía, pues llegaron propuestas más tarde, como es el caso de El desertor o el ballet La niña de plata y oro (1936-1937, según Acner, 1998), música de José Muñoz Molleda y libreto de Tomás Borrás.

Este ambiente envuelve la composición de El desertor enmarcada dentro de la eclosión creativa que experimentó España en los años veinte y treinta. $Y$, como cabe presuponer, en El desertor Ximénez de Sandoval continuó de una manera personal los preceptos creativos de su entorno. Sin embargo, la disolución definitiva en 1929 de la compañía los Ballets Espagnols de la Argentina, que intentó retomarla sin éxito, sumada a la muerte de la bailarina y la irrupción de la Guerra Civil justo el mismo día, parecen la razón más lógica para explicar por qué el ballet continúa inédito en nuestros días y puede ser una pista para comprender la interrupción de la escritura de dramaturgias dancísticas para el autor madrileño.

Aun así, por los datos que se tienen mediante la prensa y programas de manos, Ximénez de Sandoval escribió otro ballet, La rosa viva, junto a Vicente Vila-Belda. Este dramaturgo de posguerra cosechó varios éxitos con ballets como El pescador y la luna (1958), Jugando al toro (1959) o Eterna Castilla (1965). Parte de estos datos han sido extraídos de Acker (1998), en donde se indica que la composición al alimón entre Ximénez de Sandoval y Vila-Belda se produjo en 1957.

Esta vez, con más fortuna, se estrenó el ballet La rosa viva el jueves 10 de marzo de 1966 en el Teatro de la Zarzuela con música de José Muñoz Molleda, otro autor asociado a Antonia Mercé por su ballet La niña de plata y oro. La coreografía e interpretación del personaje protagonista corrió a cargo de Mariemma que, según Ximénez de Sandoval, "ha sido considerada con justicia como la sucesora de Antonia Mercé 'la Argentina', por su extraordinario conocimiento de la danza en todos sus aspectos y, concretamente, la de pura raigambre nacional, que interpreta con absoluta fidelidad dentro de la exquisita 
estilización" (Sandved, 1962: 1523, s. v. Mariemma). Sobre este ballet, cuya dramaturgia no hemos logrado localizar aún, tan solo se sabe que englobaba "una serie de danzas, con gracia melódica y ritmos diversos" (Galindo, 1966).

\section{Análisis del ballet El desertor (1930):}

El libreto de El desertor se ha localizado en el Fonds Argentina de la Bibliothèque-Musée de l'Opéra (París) en la pièce 38, $n^{\circ} 11,9$ feuilles $^{3}$. En la primera página, debajo de los paratextos del título y subtítulo, se añade la dedicatoria "a Antonia Mercé", clave en la contextualización e interpretación de este ballet. Al final del libreto encontrado, se encuentra la firma hológrafa del autor y se fecha el texto en Madrid en marzo de 1930.

A pesar de que actualmente se está realizando el epistolario de la bailarina, hasta el momento no se ha encontrado ninguna carta del autor o alguna mención de la fecha del envío del ballet de Ximénez de Sandoval, por lo que se desconoce cómo llegó a manos de la Argentina. Quizá, en alguna vuelta de Antonia Mercé a Madrid, se lo diese en mano. No obstante, sí intuimos que la bailarina lo leyó porque parecen suyas las anotaciones de los números de la partitura en relación con la acción del texto dramático, que son comunes en otros libretos que llegó a representar, como El fandango de candil o Juerga, en las versiones conservadas también en el Fonds Argentina de la Bibliothèque-Musée de l'Opéra.

La única noticia de la existencia de El desertor que da su propio autor se encuentra en la "Autobiografía" que incluye como pórtico de la edición príncipe de Tres mujeres más Equis (1930). Este texto resulta fundamental para desentrañar la profusa obra que escribe en estos años el dramaturgo madrileño, pues se pueden sumar más de una decena de obras concebidas entre 1925 y 1930. Del ballet, tan solo indica su dedicatoria y "que está poniendo música Gustavo Pittaluga" (Ximénez de Sandoval, 1930c). Por ello, es más fácil entender la trascendencia del artículo de La Gaceta Literaria anteriormente citado del mismo año porque, al mismo tiempo que Ximénez de Sandoval

\footnotetext{
${ }^{3}$ Agradezco enormemente la colaboración de Idoia Murga Castro, Blanca Gómez Cifuentes y Raquel López Fernández para poder realizar esta investigación y acceder al texto de Felipe Ximénez de Sandoval.
} 
protestaba por la falta de interés en España por la música contemporánea, auspiciada por instituciones extranjeras, y ensalzaba a Antonia Mercé que no había tenido aún oportunidad de estrenar La romería de los cornudos, estaba preparando su proyecto balletístico. A pesar de sus quejas, sería la Compañía de Bailes Españoles de la Argentinita quien asumiría el estreno de La romería de los cornudos en 1933 con escenografía de Alberto Sánchez.

A continuación, se analiza sucintamente el libreto conservado de 9 páginas en donde se recogen la síntesis de la partitura, aún sin localizar, y los tres cuadros del ballet. Debido a la poca extensión, este estudio pretende ser un primer acercamiento al texto desde una perspectiva contextual con la intención de entender el imaginario de El desertor dentro de la producción de su autor, del proyecto de los Ballets Espagnols, de las dramaturgias para ballets de la Edad de Plata y de la proyección de los estereotipos de la danza española.

Antes de analizar el texto, resulta cuanto menos curioso tener en cuenta la denominación balletística que utiliza Ximénez de Sandoval para El desertor, ya que se aleja de las propuestas de otros creadores. El dramaturgo madrileño prefiere la denominación 'ballet', como Mauricio Bacarisse para su Corrida de feria. Por un lado, esta opción se aleja de la tentativa de libretistas con voluntad de encontrar una versión española para nombrar estas piezas. La mayoría optó por 'bailete' como en el caso de Sonatina, de Ernesto Halffter, Juerga, de Tomás Borrás, o El fandango de candil, de Cipriano Rivas Cherif, quien llegó a escribir más de doce ballets para la Argentina. También se puede hallar la variante 'bailable', como en el caso de La maja vestida, de Mauricio Bacarisse, o algunas piezas incluidas en Tam tam (1931), de Tomás Borrás. Por otro lado, esta denominación de 'ballet' asume la progresiva independencia de este género dancístico de la pantomima teatral a la que estaba especialmente vinculado, como se puede observar en el cuarto movimiento de El desertor que incluye una pequeña escena mimada. Un ejemplo en la categoría 'ballet-pantomima', siempre dentro de la producción textual creada en torno a Antonia Mercé, es Nuit 
au musée, de Carlos de Batlle ${ }^{4}$.

Antes de adentrarnos en el análisis de la acción, el espacio y los personajes dramáticos, se ha de establecer una reflexión sobre la literaturización y estilización de la escritura de ballet de Ximénez de Sandoval que se asemeja a los procedimientos de Valle-Inclán en sus acotaciones o de Ramón Gómez de la Serna y Tomás Borrás en sus escrituras para danza de difícil categorización. Ximénez de Sandoval, al igual que en sus novelas, explora un estilo poético y evocador, en donde busca nuevas imágenes a partir del "principio de la percepción productiva, que descubre lo maravilloso y lo excepcional en lo cotidiano, y cuya expresión favorita son la metáfora y la metamorfosis" (Albert, 2003: 169). De esta manera, se observa la influencia de las vanguardias en la pluma del madrileño.

En El desertor, parece significativa la íntima unión entre los personajes y la danza, como si fuese congénita a ellos. En algunas prosopografías, emplea esta manera de presentar al personaje, como en el caso del Clérigo: "breviario entre las manos y el ritmo de habanera enganchado en los bajos de la sotana como en una bata de cola" (Ximénez de Sandoval, 1930b: 4-5). Llama la atención cómo indica el comienzo de un número dancístico: "en el cuerpo de Morena, un tango" (Ximénez de Sandoval, 1930b: 6). La escritura del ballet es un ejercicio en sí mismo poético que, como en el caso de las acotaciones teatrales, crea una paradoja entre la lectura y la representación, como ocurre en el ejemplo siguiente en que el autor utiliza sus comunes metáforas encadenadas: "Las gaviotas tienen un vuelo retorcido de cadencia final de fandanguillo. Lejos, campanas por soleares. Guitarras por peteneras. Castañuelas. Colleras. Herraduras." (Ximénez de Sandoval, 1930b: 3). La imaginería de la danza española se metamorfosea, pues, en los elementos descritos.

En cuanto a la acción dramática, se prioriza una trama amorosa, a la manera de los ballets clásicos románticos y emulada en la producción española. Sobre este asunto téngase en cuenta las palabras de Rivas Cherif (1931) que

\footnotetext{
${ }^{4}$ Todos estos ballets forman parte del repertorio que los autores escribieron para la Argentina, aunque no llegó a representar ni una tercera parte de las propuestas que, actualmente, edito para su publicación.
} 
comentaba que en el programa de la Argentina "se concierta con depurado gusto lo clásico y lo popular, dando por fruto el más gracioso romanticismo que hayan dado los siglos al baile español".

Dentro del reportorio creado para Antonia Mercé, por consiguiente, esta lucha por el amor de una mujer se origina en un ambiente de reminiscencias románticas, por lo general de ambientación festiva y marginal de cierto componente trágico que amenaza con acabar la celebración, como en Juerga, El contrabandista, El fandango de candil o Corrida de feria. Por tanto, las fábulas se caracterizan por una sencillez a veces ingenua y poseen ya un componente dancístico en sí mismo, como en La gitanilla o La bailarina del rey de Baviera, de Rivas Cherif.

En el caso de El desertor, un Contramaestre estadounidense llega a un puerto andaluz en donde asiste a una tarde de alborozo llena de cantes y bailes. Allí conoce a una gitana, Morena, que lo seduce y provoca un duelo de baile entre el Contramaestre y el Novillero por su amor, aunque la bailaora abandona el lugar antes de resolverse la cuestión. El Contramaestre, borracho, recuerda a Morena danzando en un sueño del que no puede salir a pesar de la retreta para que vuelva al cuartel.

La acción transcurre en dos espacios. Por un lado, los cuadros primero y tercero se sitúan en un puerto de Andalucía, lo cual destaca en comparación con el resto de los ballets propuestos a Antonia Mercé más influenciados por el madrileñismo de la época. Esta referencia continua al mar, no obstante, es propia de la obra de Ximénez de Sandoval que recurre al espacio marítimo como símbolo del misterio y de la incertidumbre de la vida humana, pero también como símbolo del escapismo que anhela el escritor. Por otro lado, el cuadro segundo ocurre al aire libre en una zona suburbial en donde se reúnen marineros, gitanos, vendedores, húsares y otras personas del lumpen. Esta ambientación recurrente conecta con las dramaturgias de Juerga, de Borrás, situada en las calles de un Madrid festivo, Triana, de Arbós, localizada en una taberna sevillana o El fandango de candil, de Rivas Cherif, ubicada en un chamizo de Lavapiés.

Con relación al tiempo, recálquese que el ballet respeta la unidad de tiempo, pues la acción dramática comienza en una tarde de verano y finaliza a 
medianoche. La presencia de la noche, propia del neorromanticismo de Ximénez de Sandoval, permite el juego con los signos lumínicos, reforzados por la atmósfera de ensoñación.

Desde el punto de vista coreográfico y musical, se advierte en la dramaturgia un profundo conocimiento de los ritmos de la época. En este sentido, el autor propone una verdadera fusión entre la danza española y los nuevos ritmos de raíz afroamericana, que se pusieron de moda en los años veinte. Así pues, se sugieren números en que se bailen habaneras, pasodobles, farrucas, tangos, fandanguillos e, incluso, un chotis, que se sale del imaginario de la Argentina, sumados al charlestón o el rag-time. En cierta medida, en El desertor, Ximénez de Sandoval cumple la máxima que defendía Antonia Mercé: "pretendo haber realizado la fusión de dos danzas: la española y la llamada ‘moderna'” (Mercé y Luque, 1917). No obstante, la bailarina centró su creación en la estilización de los bailes folklóricos españoles más que en esa fusión.

Además, el dramaturgo prestó una atención considerable a la futura escenificación. Para los marineros, indica que "agiles — deportistas, gimnastasbailan el vals, geométrico, cortado, dibujado" (Ximénez de Sandoval, 1930b: 4). Los acompañantes del Novillero se comportarán como "imitadores conscientes del ídolo" (Ximénez de Sandoval, 1930b: 6). Destaca en especial en uno de los momentos climáticos del ballet, el número de la "Danza de los achares" en donde comienza la rivalidad del Contramaestre y el Novillero para conseguir el amor de Morena. Aunque da una gran libertad coreográfica, se acentúa la actitud de los personajes que se muestran "frenéticos en sus mesas, alternativamente de pie o sentados, como muñecos para el juego plástico de la bailadora" (Ximénez de Sandoval, 1930b: 6-7). De esta manera, Ximénez de Sandoval, a lo largo del ballet, da pistas para la composición coreográfica con una tendencia a la simetría: en el primer cuadro centrado en el Contramaestre, en el segundo en los tres personajes centrales y distribuida la atención entre Morena y el Contramaestre en el tercer cuadro.

En este trabajo, creo importante analizar el funcionamiento del imaginario de lo español en convivencia con otros imaginarios, ya que Antonia Mercé proyectaba una idea de España estereotipada, una herencia estilizada de la 
españolada que estuvo de moda en París. Es más, ya Tomás Borrás advirtió a la bailarina de que algunas decisiones tomadas en relación a Juerga, estrenada el 9 de junio de 1929 en la Opéra Comique de París, no tendrían sentido si se hubiese representado en el ámbito nacional, puesto que no se adscribe a la realidad que el espectador conoce: "Ahora si sus designios de V. son solamente presentar el bailete en el extranjero, donde tienen una visión falsa de lo español, entonces hay un gran margen" (Borrás, s.a.: 2).

Por ello, tener en cuenta que Ximénez de Sandoval utiliza dos imaginarios no es baladí, ya que terminará decantándose por la identidad española codificada como un embrujo que envuelve a la otredad. Así pues, presenta dos visiones preconcebidas del mundo estadounidense y del hispánico.

El primero, el del Contramaestre, aparece asociado a la modernidad, al sonido del acordeón, a los ritmos del rag-time y el charlestón y al mundo del deporte (boxeo, base-ball, rugby), referentes todos ellos de la vanguardia. La elección de personajes dentro de estos esquemas, más comunes en la narrativa del momento, no suelen aparecer en las dramaturgias balletísticas. No obstante, existen propuestas con un imaginario estadounidense en La botella borracha, de Tomás Borrás, incluido en Tam tam (1931).

En oposición, con un sentido "muy ritual, muy flamenco" (Ximénez de Sandoval, 1930b: 8), se presentan como signo de lo español el toreo, los movimientos de la farruca, los sombreros cordobeses y el sonido de la guitarra. Desde este punto de vista, Ximénez de Sandoval trabaja con dos realidades que, antes de la lidia, ya están destinadas a enfrentarse, como si se tratara de los binomios civilización/barbarie o modernidad/antigüedad.

Esta confrontación no es más que la rivalidad generada por dos modelos de masculinidades guiadas en esencia por el mismo objetivo: conseguir a Morena, en el sentido más objetual y pornotópico. En este caso, llama la atención que Ximénez de Sandoval escoja un novillero más que un torero, quizá porque este último hubiese sido por definición el protagonista de la trama. Como es común en la época, y en el corpus textual de ballets españoles, mantiene el aire bravío y competidor, sin el matiz trágico que, por ejemplo, explora Mauricio Bacarisse en Corrida de feria. En cambio, en el Contramaestre se elige una 
categoría dentro de la marinería que le da un estatus superior, en donde se puede apreciar un cierto patrón común en los personajes masculinos de las dramaturgias españolas para ballet: los hombres adquieren protagonismo por una distinción de clase social, por pretender un amor imposible, por atentar contra el orden legal-social o por una combinación de las opciones anteriores, como en el caso del Contramaestre. Su protagonismo en la trama se constata por su aparición en todos los cuadros y por la experimentación de un arco de evolución crucial para entender el ballet. Esta decisión dramatúrgica, que resta foco al lucimiento de la bailarina que interpreta a Morena, probablemente fuese uno de los argumentos para que Antonia Mercé no llegara a representarlo, sumado a la desaparición de los Ballets Espagnols.

El arco de evolución del Contramaestre está íntimamente ligado a la seducción del tango de Morena, una visión sobre la mujer bailarina común en la época de tono simbolista si se tiene el recuerdo de las Salomés finiseculares. Pero, sin duda, detrás de esta propuesta dramatúrgica se advierte una influencia de Carmen, ópera con música de Georges Bizet y libreto de Ludovic Halévy y Henri Meilhac estrenada en 1875. Esta bailarina gitana latía detrás del concepto francés de lo español que los artistas españoles exportaron, como suyo, en el auge del género de la españolada. Aunque se popularizó por medio de la ópera, el hipotexto es una novela homónima de Prosper Merimée publicada en 1847. Si el ballet tuviese una duración mayor, puesto que la fábula dura en torno a seis horas, cabría pensar que el destino del Contramaestre está ligado al de Don José, un exmilitar que abandona todo por Carmen. He ahí la clave del título del ballet de Ximénez de Sandoval: el desertor.

Tras la presentación en el primer cuadro de los marineros estadounidenses recién llegados, el Contramaestre se encuentra con Morena en el segundo cuadro que, como la Niña Bonita de El fandango de candil, de Rivas Cherif, pretende ser el centro de la fiesta. Hacia el final del cuadro, después de la competición dancística, comienza el declive inexorable del Contramaestre. Este momento tan significativo es una síntesis de diferentes aspectos hasta ahora analizados, pues Ximénez de Sandoval imagina una escena confusa, en donde los dos imaginarios (el español y el estadounidense) comienzan a 
confundirse incluso coreográficamente: "El baile está ahora perturbado y nadie sabe lo que baila. La habanera se disfraza de charlestón y de farruca" (Ximénez de Sandoval, 1930b: 8$)^{5}$.

En el cuadro tercero ya el Contramaestre ha experimentado la mimetización con lo español y ha comenzado su camino de no retorno hacia la deserción: "Trae arrastrando una guitarra y, en vez del gorrito de piqué de marinero, el cordobés del Novillero" (Ximénez de Sandoval, 1930b: 8). En este momento, el dramaturgo madrileño acude a uno de sus recursos literarios más comunes: el sueño; porque "la indistinción entre sueño y realidad es característica del escapismo de la vanguardia prefascista, de su irracionalismo y de su eliminación de la realidad social" (Albert, 2003: 233). La pérdida de Morena y la embriaguez provocan en el personaje un estado de ensoñación muy evocador para la puesta en escena.

Por tanto, vigilia y sueño se entremezclan para el espectador que, a su vez, no es capaz de determinar los límites de la ficción y de la realidad dentro del plano diegético. Brota, así, una Morena que baila en el recuerdo del Contramaestre: "en el silencio de la noche, una guitarra suena. Más fantástica, más estilizada, la sombra de Morena se hace — sin romperse ni mancharselos mil pedazos del tango" (Ximénez de Sandoval, 1930b: 9). Como bien advierte Albert (2003:170) en su análisis de Tres mujeres más Equis,

en la base de esta visión catastrófica se encuentra una "locura visual" provocada por la ausencia de la amada, que ordenaba el campo visual como punto de fuga. [...] La pérdida del objeto central causa una escisión entre el sujeto y su percepción alienada.

En el caso de El desertor, esta "locura visual" adquiere un sentido aún más plástico que, de haber sido representado, hubiese supuesto un complejo ejercicio poético para la concepción coreográfica, luminotécnica y escenográfica.

Esta escena evoca en el espectador y los marineros la misma sensación

\footnotetext{
5 Téngase en cuenta que la farruca ha sido un género coreográfico tradicionalmente asociado a las masculinidades que, en este ballet, adquieren una configuración particular que abre la puerta, incluso, a interpretaciones homoeróticas. En relación con las cuestiones de género en la farruca, cf. LÓPEZ RODRÍGUEZ, Fernando (2016). "Espejismos de la identidad coreográfica: estética y transformaciones de la farruca", en Academia de las Artes Escénicas de España, I Premio de Investigación de la Academia. Madrid: AAEE/INAEM, 11-79 pp.
} 
que viven otros personajes de Ximénez de Sandoval. Cabe recordar el final del cuento "Dolorosa", en que un legionario, José Fernández, narra a sus compañeros que se ha aventurado a ir al Madrid sitiado de la Guerra Civil por amor:

¿Era todo una verdad o una mentira legionaria, igualmente líricas una u otra? $\mathrm{Ni}$ el narrador ni los oyentes lo sabían ya. Pero en el sueño de todos, aquella noche de calma en el sector, hubo una mujer de nardo con orejas, que se parecía, como una estrella a otra, a Dolorosa. (Ximénez de Sandoval, 1938)

En el caso de El desertor, los marineros también experimentan la evocación del Contramaestre, lo que crea un enmarañamiento de sueño y ficción. Es más, la escena deviene en episodio homérico y Morena embelesa con su "baile [que] tiene frenesí de pasión sonámbula y los marineros, persiguiendo para besar la sombra escurridiza de Morena, se encuentran unos con otros y se besan y abofetean entre ellos, con actitudes de payasos" (Ximénez de Sandoval, 1930b: 9).

Este momento climático llega a su fin con el sonido de la retreta, esto es, el toque militar que llama al cuartel por las noches. Todo vuelve a la vigilia, al orden, a la realidad de la que se había salido en una suerte de fantasía onírica. Los marineros salen de escena capaces de renunciar a la abducción dancística de Morena. Sin embargo, el Contramaestre se tapa los oídos y permanece absorto ante la danza fantasmagórica de la gitana. El personaje ya ha culminado su proceso irrevocable de deserción que, iconográficamente, se ha convertido en un alegato escénico en favor de la hegemonía de lo español al no lograr "cubrir con sus notas metálicas [de corneta] las cadencias de la guitarra" (Ximénez de Sandoval, 1930b: 9).

La elección de la evasión y del sueño en la poética de Ximénez de Sandoval es un topos recurrente en sus personajes que intentan huir de la sociedad contemporánea al mostrarse como un espacio viciado y atormentado por el esplín. De manera similar a como ocurre en Robinsón (1928), el Contramaestre intenta encontrar una manera de aislarse a través del amor, el deporte o la danza. En definitiva, todas ellas son vías para la deserción de la realidad porque, como sentencia Albert (2007: 420), "el mensaje históricofilosófico del joven dramaturgo español se opone diametralmente al optimismo 
ilustrado de Occidente con su idea de progreso y perfectibilidad".

\section{Conclusiones y sueños para la danza}

Aunque tan solo se haya localizado hasta ahora El desertor y no se tengan noticias del ballet La rosa viva que escribió para Mariemma, el interés de Ximénez de Sandoval trasciende este tipo de escritura intermedial y afecta a su producción literaria en la que se pueden rastrear otras formas de reivindicación del arte coreográfico. Sobre todo, es en su teatro donde se emplea la danza como mecanismo dramatúrgico. Son significativos los ejemplos, que se deben de estudiar con profundidad, de Robinsón (1928) en donde la danza griega simboliza el culto por la armonía y la forma; y de Mercedes "la gaditana" (1932), escrita junto a Sánchez de Neyra, en donde el flamenco brota de la garganta y los pies de una mujer que sufre de achares.

Además, Ximénez de Sandoval tuvo una consciencia clara del camino frustrado que había llevado la danza española hasta los sesenta por "la falta de un teatro adecuado y de una protección oficial [que] dispersó el interesante intento" (Sandved, 1962: 212, s. v. ballet). Desde esta perspectiva, el autor, que conoció esta situación, bien pudo suponer que la frustración de los Ballets Espagnols de Antonia Mercé, la Argentina, en 1929 era el trasunto de un naufragio mayor, esto es, el proyecto de creación de una estructura para el ballet en España. Con los Ballets Espagnols, probablemente, también se vio truncada cualquier posibilidad de representación de El desertor. Ximénez de Sandoval, aun así, continuó con una pequeña esperanza:

Sería necesario contar con un local adecuado, una fuerte subvención, un director enérgico y una férrea disciplina que evitase las frecuentes dispersiones. Quizá el día que terminen las obras del Teatro Real, de Madrid, se consiga lo que hoy parece un sueño. (Sandved, 1962: 212, s. v. ballet)

En definitiva, con El desertor, Ximénez de Sandoval ofreció su pluma para contribuir a la consolidación, dignificación e intelectualización de la danza española. Concibió, además, una dramaturgia que exploraba nuevos imaginarios, aunque continuaba la ambientación flamenca y el gusto cañí. Propuso nuevos ritmos propios de la sociedad europea del momento, como el charlestón y el rag-time, que se fusionarían, de haberse compuesto la partitura 
de Pittaluga, con la música folklórica o de raigambre nacionalista que llevaban reivindicando los músicos españoles del primer tercio del siglo $\mathrm{XX}$. Pero, sobre todo, con El desertor, Ximénez de Sandoval tuvo sueños para una nueva danza española.

\section{BIBLIOGRAFÍA}

$A B C$ (1931). "Homenaje a Antonia Mercé (La Argentina)", ABC edición de Andalucía, 3-12-1931, p. 29.

ACKER, Yolanda (1998). "Ballets escritos por compositores españoles en el siglo XX". En Antonio Álvarez Cañibano, José Ignacio Cano y María José González Ribot (eds.), Ritmo para el espacio. Los compositores españoles y el ballet en el siglo XX. Madrid: Centro de Documentación de la Música y de la Danza, 42-67 pp.

AlBERT, Mechthild (2007). "Esteticismo neoclásico y vitalismo prefascista. Felipe Ximénez de Sandoval: Robinsón". En Gero Arnscheidit y Pere Joan Tous (coords.), Una de las dos Españas: representaciones de un conflicto identitario en la historia y en las literaturas hispánicas: estudios reunidos en homenaje a Manfred Tietz. Madrid/Frankfurt: Vervuert/lberoamericana, 403-422 pp.

Albert, Mechthild (2003). Vanguardistas de camisa azul. La trayectoria de los escritores Tomás Borrás, Felipe Ximénez de Sandoval, Samuel Ros y Antonio de Obregón entre 1925 y 1940. Traducción de Cristina Díez Pampliega y Juan Ramón García Ober. Madrid: Visor.

Bethencourt Pérez, Fátima (2016). La escena moderna como crisol de la vanguardia: su reflejo en el ballet La romería de los cornudos y el espectáculo La Tragedia de Doña Ajada (1929) [tesis]. Madrid: Universidad Complutense de Madrid.

BorRÁs, Tomás (s.a.). "Carta a Antonia Mercé” [inédita], MAE, Institut del Teatre, n. 12865, 2 pp.

Carbajosa, Mónica, y Carbajosa, Pablo (2003). La corte literaria de José Antonio: la primera generación cultural de la Falange. Barcelona: Crítica.

FISCHER-LICHTE, Erika [1983] (1999). Semiótica del teatro. Traducción de Elisa Briega Villarrubia. Madrid: Arco/Libros, Col. Perspectivas.

GALINDO, Federico (1966). "Crónica teatral. Juguetes para un matrimonio, nueva obra de Alfonso Paso. Apasionado clima en el Ateneo durante una representación teatral. Las Melodías vascas de Guridi convertidas en ballet", Diario de Burgos, 17-3-1966, p. 12.

Hellín RuBio, Inés (2106). La Danza Española y la narrativa escénica. Madrid: Publicaciones de la Asociación de Directores de Escena de España, col. Teoría y práctica del Teatro.

MERCÉ y LUQUE, Antonia (s.a.). "Entrevista a Antonia Mercé". Fondo Antonia Mercé, MAE, Institut del Teatre, n. 12916. Barcelona, p. 73.

MERCÉ y LUQUE, Antonia (1926). "La Argentina y el baile español", Heraldo de Madrid, 26-09-1926, p. 26.

MERCÉ Y LUQUE , Antonia (1917). “El baile español”, Thalia, 15-09-1917. 
Murga CAStRo, Idoia (2017). Escenografía de la danza en la Edad de Plata (1916-1936). Madrid: Consejo Superior de Investigaciones Científicas.

RIVAS CHERIF, Cipriano (1931). "Embajadora extraordinaria", El Sol, 2-12-1931, p. 8.

RuIz CocA, Fernando (1980). "El baile español entre lo popular y lo culto", Ya, 212-1980, pp. 22-23.

Sandved, Kjell B. (dir.) (1962): El mundo de la música: guía musical. Trad. Felipe Ximénez de Sandoval.

VV. AA. (1930): “Una encuesta sensacional. ¿Qué es la vanguardia?”, La Gaceta Literaria (julio), n. 86, 3-4 y 15 pp.

XIMÉnEZ DE SANDOVAL, Felipe (1938). "Dolorosa", Vértice (agosto), n. 13, p. 56.

XIMÉNEZ DE SANDOVAL, Felipe (1930a). "Bajo el signo de la UMFE", La Gaceta Literaria (agosto), n. 88, p. 9.

XIMÉNEZ DE SANDOVAL, Felipe (1930b). El desertor [inédito], Fonds Argentina, Bibliothèque-Musée de l'Opéra, pièce 38, n. 11, 9 pp.

XIMÉnEZ DE SANDOVAL, Felipe (1930c). Tres mujeres más Equis: novela lírica. Madrid: Ulises, Col. Valores Actuales.

XiméneZ de SANDOVAL, Felipe (1928). "Ernesto Halffter y su primer cuarteto", Asociación de Cultura Musical, año VII, 1927-1928, 30-04-1928, s/p.

Fecha de recepción: 7 de enero de 2020

Fecha de aceptación: 24 de marzo de 2020 